\title{
Verandering en ontwikkeling in Big Five-persoonlijkheidsfactoren tijdens de adolescentie
}

\author{
Susan J.T. Branje • Cornelis F.M. van Lieshout • Marcel \\ A.G. van Aken • Jan R.M. Gerris
}

\begin{abstract}
Dit onderzoek richt zich op ontwikkeling van de persoonlijkheid tijdens de adolescentie. Twee adolescente kinderen uit 285 twee-oudergezinnen beoordeelden in drie meetronden met tussenpozen van een jaar hun eigen en elkaars persoonlijkheid. Ook beide ouders beoordeelden de persoonlijkheid van de adolescenten. Persoonlijkheid bleek gemiddeld stabiel over tijd, maar voor een aanzienlijke subgroep was er sprake van een aanzienlijke intra-individuele verandering. Versnelde groeicurveanalyses toonden aan dat Aangenaamheid en Openheid toenamen bij adolescenten van elf tot zeventien jaar en dat voor meisjes Zorgvuldigheid toenam en Emotionele stabiliteit afnam. Resultaten bevestigden dat er gedurende de adolescentie persoonlijkheidsontwikkeling plaatsvindt, maar dat de aard van deze veranderingen ook afhangt van het type beoordelaar.
\end{abstract}

\section{Inleiding}

Dit onderzoek is gericht op niveauveranderingen in persoonlijkheid gedurende de adolescentie. Persoonlijkheidskenmerken worden beschouwd als biologisch gebaseerde disposities, die bepaald worden in de kindertijd en adolescentie, en stabiliteit vertonen over tijd (bijv. McCrae \& Costa, 1994). Bij onderzoek naar stabiliteit en verandering van persoonlijkheid gaat het vaak om zogenaamde rangordestabiliteit. Personen die op een bepaald moment relatief hoog scoren op een persoonlijkheidsdimensie in vergelijking met anderen, blijven na verloop van tijd hoog scoren. Personen die relatief laag scoren,

Susan J.T. Branjeen, Universiteit Utrecht, Faculteit Sociale Wetenschappen, Kinder- en Jeugdstudies. Postbus 80140, 3508 TC Utrecht, e-mail: s.j.t.branje@fss.uu.nl. blijven relatief laag scoren. De stabiliteit van individuele verschillen in persoonlijkheid van kindertijd tot volwassenheid is redelijk (Caspi, 1998, 2000; Caspi \& Roberts, 1999, 2001; Stein, Newcomb \& Bentler, 1986) en neemt toe met leeftijd (Roberts \& Delvecchio, 2000). Een hoge rangordestabiliteit kan echter heel goed gepaard gaan met een hoge mate van gemiddelde verandering, ofwel gemiddelde afname of toename, in persoonlijkheidskenmerken.

Vanuit een ontwikkelingsperspectief kan persoonlijkheidsverandering het gevolg zijn van intrinsieke, levensloopgerelateerde, normatieve ontwikkeling (Baltes, 1987; McCrae e.a., 2000). Als gevolg van socialisatie worden mensen beter aangepast naarmate ze ouder worden. Daardoor zijn ze bijvoorbeeld minder impulsief, houden ze zich meer aan normen, hebben ze meer sociale vaardigheden en zijn ze wijzer. Ontwikkeling kan ook het gevolg zijn van normatieve maar meer historisch en cultureel bepaalde, cohortspecifieke contextuele veranderingen en rolveranderingen, die mannen en vrouwen gedurende hun levensloop tegenkomen, zoals werk, huwelijk en ouderschap (Srivastava, John, Gossling \& Potter, 2003; Van Lieshout, 2000). Het betreden van de arbeidsmarkt kan bijvoorbeeld van adolescenten en jongvolwassenen vereisen dat ze zich zorgvuldiger gaan gedragen. In een contextuele benadering van persoonlijkheid, die suggereert dat persoonlijkheid flexibel is en kan veranderen (Lewis, 1999), wordt het belang van dergelijke levensgebeurtenissen en roltransities voor de verandering van persoonlijkheid benadrukt. De adolescentie is een periode waarin belangrijke lichamelijke, cognitieve en sociale veranderingen optreden, wat persoonlijkheidsverandering tot gevolg kan hebben.

Het huidige onderzoek richt zich op ontwikkeling of gemiddelde niveauverandering van de Big Five- 
persoonlijkheidsfactoren Extraversie, Aangenaamheid, Zorgvuldigheid, Emotionele stabiliteit en Openheid voor ervaringen (Goldberg, 1990, 1993) in de adolescentie. De Big Five-persoonlijkheidsfactoren zijn gevonden in talrijke studies die gebruik maakten van verschillende methoden, instrumenten, steekproeven, talen en culturen (Costa \& McCrae, 1992; Digman, 1990; Goldberg, 1990; John, 1990; McCrae \& Costa, 1997, 1999) en zijn verenigbaar met diverse andere persoonlijkheidsmodellen (Shiner, 1998, Van Lieshout, 2000). Ze zijn gevonden in steekproeven van kinderen en adolescenten, zowel bij jongens als meisjes, in beschrijvingen van ouders en leerkrachten (Asendorpf \& Van Aken, 2003; Graziano \& Ward, 1992; Robins, John \& Caspi, 1994; Van Lieshout \& Haselager, 1994) en kunnen in de adolescentie betrouwbaar vastgesteld worden met instrumenten voor volwassenen (Costa \& McCrae, 1994; De Fruyt, Mervielde, Hoekstra \& Rolland, 2000).

De Big Five-persoonlijkheidsfactoren in het kort.

1. Extraversie reflecteert de hoeveelheid en intensiteit van interpersoonlijke interactie en activiteitenniveau, ofwel de mate waarin de persoon intensieve ervaringen opzoekt en actief is of juist intensieve ervaringen en activiteiten vermijdt.

2. Aangenaamheid heeft betrekking op de interpersoonlijke aard van de persoon, variërend van warm, coöperatief en betrokken bij anderen tot tegenwerkend.

3. Zorgvuldigheid betreft de mate van organisatie, doorzettingsvermogen, motivatie en weerstand bieden aan impulsen en verleidingen bij het uitvoeren van doelgericht taakgedrag.

4. Emotionele stabiliteit heeft betrekking op de regulatie van emoties en meet de mate waarin een persoon emotioneel stabiel is of juist snel overstuur raakt en geplaagd wordt door onplezierige emoties.

5. Openheid voor ervaringen geeft aan in hoeverre een persoon brede interesses heeft, actief ervaringen opzoekt en apprecieert, flexibel informatie verwerkt en geneigd is tot tolerantie en exploratie van het onbekende.

Over het algemeen scoren adolescenten hoger op Extraversie en Emotionele stabiliteit en lager op Aangenaamheid en Zorgvuldigheid dan volwassenen (Costa \& McCrae, 1994; McCrae e.a., 2000). Tussen twaalf en achttien jaar neemt het gemiddelde niveau van zelfgerapporteerde Openheid toe voor zowel meisjes als jongens en neemt Emotionele stabiliteit af voor meisjes, terwijl gemiddelde niveaus van Extraversie, Aangenaamheid en Zorgvuldigheid niet veranderen (McCrae e.a., 2002). Een recent onderzoek onder Estlandse jongeren van twaalf tot achttien jaar vond een lichte toename in Openheid en afname in
Aangenaamheid en Zorgvuldigheid (Allik, Laidra, Realo \& Pullmann, 2004). Onder studenten zijn toenamen in Openheid, Aangenaamheid en Zorgvuldigheid gevonden, evenals afnamen in Extraversie en Emotionele stabiliteit (Gray, Haig, Vaidya \& Watson, in McCrae e.a., 2002; Robins, Fraley, Roberts \& Trzesniewski, 2001; Vaidya, Gray, Haig \& Watson, 2002), hoewel Vaidya e.a. een toename voor Extraversie en geen veranderingen voor Emotionele stabiliteit vonden over een periode van 2,5 jaar. De toename in Openheid kan aangeven dat adolescenten intellectuele, artistieke, emotionele en creatieve expressies steeds meer appreciëren. De afname in Emotionele stabiliteit voor adolescente meisjes kan samenhangen met hogere niveaus van depressie en lagere niveaus van zelfwaardering, die kenmerkend zijn voor meisjes vanaf de puberteit. Uit onderzoek in verschillende culturen blijkt dat Extraversie gemiddeld afneemt gedurende de late adolescentie, terwijl Aangenaamheid, Zorgvuldigheid en Emotionele stabiliteit gemiddeld toenemen tot in de jongvolwassenheid (McCrae e.a., 2000).

Samenvattend zijn de meest consistente bevindingen dat Emotionele stabiliteit bij meisjes afneemt tijdens de adolescentie, terwijl Openheid bij jongens en meisjes toeneemt in de adolescentie en jongvolwassenheid. Gebaseerd op deze bevindingen verwachten we een afname in Emotionele stabiliteit voor adolescente meisjes en een toename in Openheid voor jongens en meisjes.

Gemiddelde veranderingen in persoonlijkheid worden meestal onderzocht met cross-sectioneel of kortetermijn-longitudinaal onderzoek. Hoewel de resultaten van cross-sectionele onderzoeken gerepliceerd zijn in cross-nationale en cross-culturele steekproeven, leveren deze studies geen doorslaggevend bewijs voor veranderingen in persoonlijkheid doordat ze individuen niet over tijd volgen. Longitudinale studies zijn vaak beperkt door de ontwikkelingstijdspanne die ze beslaan en door het aantal malen dat persoonlijkheid is vastgesteld. Door gebruik te maken van groeicurveanalyses met een versneld of cohortsequentieel longitudinaal design kunnen de voordelen van crosssectioneel en longitudinaal onderzoek gecombineerd worden. Met versnelde groeicurveanalyses zullen we de ontwikkeling van persoonlijkheid in de adolescentie van elf tot zeventien jaar onderzoeken (Biesanz, West \& Kwok, 2003).

Hoewel de groeicurveanalyses informatie geven over normatieve ontwikkeling van persoonlijkheid in de adolescentie, is het bij de analyses van gemiddelden van elkaar overlappende cohorten niet duidelijk of deze ontwikkeling ook bij individuele jongeren terug te zien is. Daarom onderzoeken we ook intra-individuele 
verandering in de persoonlijkheid van adolescente kinderen. Intra-individuele verandering betreft de toe- of afname van de scores van elk individu gedurende de duur van het onderzoek op elk van de Big Five-persoonlijkheidsfactoren (Roberts, Caspi \& Moffitt, 2001). Het gaat hierbij dus om de vraag of veranderingen binnen individuele adolescenten optreden op het niveau van persoonlijkheid over een periode van twee jaar.

Veranderingen in persoonlijkheid kunnen verschillen per bron van informatie. Zo vonden McCrae e.a. (2004) dat persoonlijkheid beoordeeld door observatoren minder veranderde dan persoonlijkheid beoordeeld door de persoon zelf. Daarom zullen we zelfrapportages en rapportages door andere gezinsleden onderscheiden en onderzoeken of persoonlijkheidsontwikkeling afhangt van de beoordelaar. Verschillen tussen zelfrapportages en rapportages door anderen kunnen afhangen van verschillen in de zichtbaarheid (Funder, 1980, 1995; Funder \& Dobroth, 1987) of de situationele relevantie van de verschillende persoonlijkheidsfactoren (Funder \& Colvin, 1991). Het is gemakkelijker om iemand accuraat en consistent te beoordelen op een persoonlijkheidsfactor wanneer de gedragingen die samenhangen met de factor duidelijk zichtbaar en in meerdere settings relevant zijn, dan wanneer ze minder zichtbaar of alleen in specifieke settings relevant zijn. Verschillende beoordelaars zijn het over het algemeen meer eens over duidelijk zichtbare aspecten van persoonlijkheid zoals Extraversie en Zorgvuldigheid, dan over meer intrapsychische factoren zoals Emotionele stabiliteit (Borkenau \& Liebler, 1992; Funder \& Dobroth, 1993; John \& Robins, 1993; Kenny, Albright, Malloy \& Kashy, 1994; Malloy e.a., 1997).

Onze hypothese is dan ook dat Emotionele stabiliteit beter te beoordelen is door de persoon zelf dan door zijn of haar gezinsleden en dat andere gezinsleden daardoor minder verandering rapporteren dan de persoon zelf. Andere persoonlijkheidsfactoren zijn duidelijker zichtbaar voor anderen en kunnen dus meer verandering vertonen in rapportages van anderen. Samenvattend luiden onze hypothesen:

1. in de adolescentieperiode treden normatieve ontwikkelingen op in met name Emotionele stabiliteit en Openheid voor nieuwe ervaringen;

2. een aanzienlijk aantal individuele adolescenten zal verandering in persoonlijkheid over tijd vertonen;

3. zelfbeoordelingen van persoonlijkheid zullen meer verandering vertonen dan beoordelingen door gezinsleden.

We zullen de ontwikkeling van persoonlijkheid voor jongens en meisjes apart bekijken om sekseverschillen te onderzoeken.

\section{Methode}

\section{Respondenten}

Deelnemers aan dit onderzoek waren 288 Nederlandse gezinnen met twee ouders en twee adolescente kinderen uit het (Nijmeegse) Gezin en Persoonlijkheid-onderzoek (Haselager \& Van Aken, 1999). De gezinnen waren willekeurig geselecteerd uit adreslijsten van volledige gezinnen met minimaal twee adolescenten, die ter beschikking gesteld waren door 23 representatieve gemeenten in Nederland. De gezinnen kregen een brief waarin het onderzoek toegelicht werd en waarin aangekondigd werd dat ze door interviewers zouden worden opgebeld om hun medewerking te vragen. Van de gebelde gezinnen wilde de helft meewerken. Enkele veelvoorkomende redenen om deelname te weigeren waren gebrek aan interesse voor het onderwerp van het onderzoek en niet mee willen doen door een van de gezinsleden. Gezinnen werden geselecteerd op een evenredige steekproefverdeling van leeftijd en sekse van de adolescenten. De gemiddelde leeftijd van de oudere adolescenten was 14,5 (variërend van 11,4 tot 16,0 jaar), de gemiddelde leeftijd van de jongere adolescenten was 12,4 (variërend van 11,0 tot 14,8 jaar). Er namen ongeveer evenveel jongens als meisjes deel aan het onderzoek.

\section{Procedure}

De gezinnen werden in drie jaarlijkse meetronden thuis bezocht door een interviewer, die aan beide ouders en de twee adolescente kinderen vroeg een reeks vragenlijsten in te vullen. De interviewer bleef bij het gezin totdat iedereen de vragenlijst had ingevuld en zag erop toe dat de gezinsleden de vragenlijsten onafhankelijk van elkaar invulden. In iedere meetronde kregen de adolescenten na het invullen van de vragenlijsten een cd-bon van 7,50 euro. $\mathrm{Na}$ de derde meetronde maakten gezinnen die driemaal hadden deelgenomen kans op een van vijf reischeques. De uitval was zeer laag: van de 288 gezinnen die in de eerste meetronde deelnamen aan het onderzoek, deden er in de derde meetronde nog 285 mee.

\section{Materiaal}

De Big Five-persoonlijkheidsfactoren werden gemeten met een Nederlandse bewerking van de Big Five-vragenlijst van Goldberg (1992). Deze bewerking maakt gebruik van dertig van de originele unipolaire honderd markers; zes markers voor elk van de vijf persoonlijkheidsfactoren (Gerris, Houtmans, Kwaaitaal-Roosen, De Schipper, Vermulst \& Janssens, 1998). Deze dertig items werden gemeten met behulp van een zevenpunts-Likert-schaal 
$(1=$ klopt helemaal niet; $4=$ klopt soms wel, soms niet; $7=$ klopt helemaal). Voorbeeld-items voor Extraversie zijn 'spraakzaam' en 'verlegen', voor Aangenaamheid 'vriendelijk' en 'behulpzaam', voor Zorgvuldigheid 'gedisciplineerd' en 'onzorgvuldig', voor Emotionele stabiliteit 'onzeker' en 'nerveus' en voor Openheid voor ervaringen 'creatief' en 'artistiek'.

Zowel beide ouders als beide adolescenten beoordeelden de persoonlijkheidskenmerken van de twee deelnemende adolescenten. Voor elke adolescent waren dus een zelfoordeel en drie oordelen van gezinsleden beschikbaar. De oordelen van de drie gezinsleden werden gemiddeld. De betrouwbaarheid (Cronbachs alfa) van de Big Five-factoren beoordeeld door de verschillende gezinsleden varieerde van 0,68 tot 0,90 voor oordelen over de persoonlijkheid van oudere adolescenten, en van 0,63 tot 0,87 voor oordelen over de persoonlijkheid van jongere adolescenten.

\section{Resultaten}

Ontwikkeling van persoonlijkheid gedurende de adolescentie

Latente groeicurvemodellen (LGM) werden gebruikt om de ontwikkeling van persoonlijkheid gedurende de adolescentie te onderzoeken (Duncan, Duncan \& Stry cker, 2001; Mehta \& West, 2000; Raudenbush \& Chan, 1993).
Tabel 1 Cohorten in het versneld longitudinale design.

\begin{tabular}{llllllll}
\hline \multicolumn{7}{c}{ Leeftijd adolescenten } \\
\hline Cohort $\left(N_{\text {jongens }} / N_{\text {meisjes }}\right)$ & 11 & 12 & 13 & 14 & 15 & 16 & 17 \\
$1(48 / 49)$ & 11 & 12 & 13 & & & & \\
$2(66 / 74)$ & & 12 & 13 & 14 & & & \\
$3(53 / 59)$ & & & 13 & 14 & 15 & & \\
$4(64 / 56)$ & & & & 14 & 15 & 16 & \\
$5(46 / 55)$ & & & & & 15 & 16 & 17 \\
\hline
\end{tabular}

Latente groeicurveanalyses richten zich op ongeobserveerde latente factoren die het onderliggende groeitraject weergeven van geobserveerde herhaalde metingen over tijd, daarbij controlerend voor het effect van meetfouten. Er werden aparte latente groeicurvemodellen geschat voor elk van de Big Five-factoren, voor jongens en meisjes apart en voor zowel de beoordeling van de adolescent zelf als voor de gemiddelde beoordeling van de drie gezinsleden (Amos5; Arbu ckle \& Wothke, 1999).

We gebruikten een versneld longitudinaal design (Duncan, Duncan \& Strycker, 2001), waarbij in multigroep-LGM's met vijf verschillende leeftijdscohorten van adolescenten lineaire veranderingen in persoonlijkheid geschat werden. Door verschillende cohorten als verschillende groepen te gebruiken, was het mogelijk veranderingen in Big Five-factoren van elf tot zeventien jaar te schatten. Tabel 1 toont het aantal adolescenten in elk

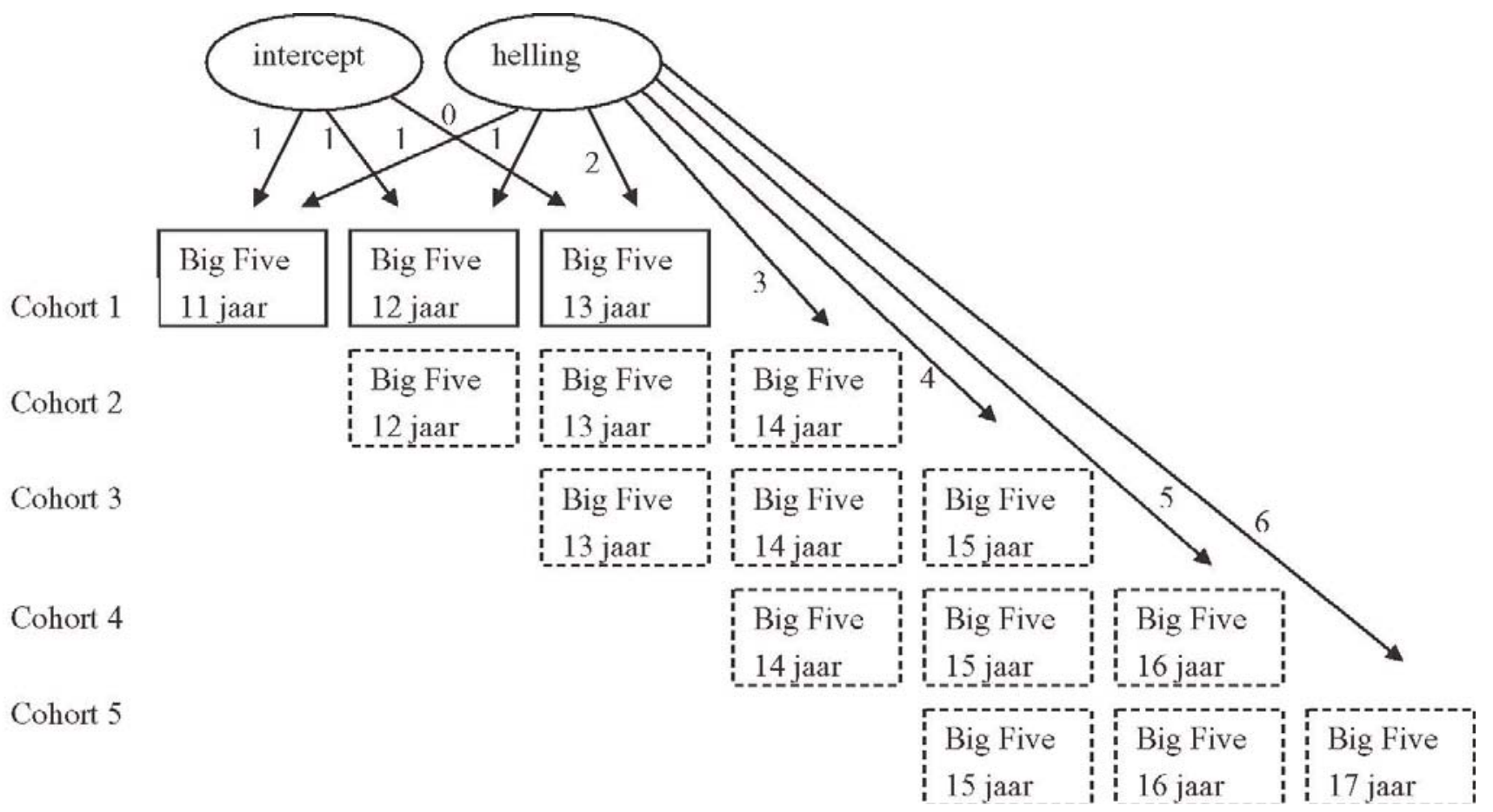

Figuur 1 Versneld lineair latente groeicurvemodel. 
cohort en hoe deze cohorten gebruikt werden in het versnelde longitudinale design. Te zien is dat de groepen adolescenten van elf tot vijftien jaar elk drie jaar gevolgd werden, waardoor de ontwikkeling van persoonlijkheid van elf tot zeventien jaar geschat kan worden. Figuur 1 toont een voorbeeld van een versneld latent groeicurvemodel.

Bij latente groeicurvemodellen wordt een gemiddeld intercept, een gemiddelde hellingscoëfficiënt en de variantie van het intercept en de hellingscoëfficiënt geschat. Het gemiddelde intercept geeft de gemiddelde beginwaarde weer van de Big Five-factor op elf jaar, terwijl de gemiddelde hellingscoëfficiënt de gemiddelde lineaire verandering weergeeft. De varianties geven interindividuele verschillen in beginniveau en in verandering weer. De geschatte parameters en de fit van de modellen worden weergegeven in tabel 2 voor zelfgerapporteerde persoonlijkheid, en in tabel 3 voor persoonlijkheid gerapporteerd door de gezinsleden. De fitindices geven aan dat de modellen een acceptabele tot goede fit hadden.

De significante gemiddelde waarden voor de intercepten (Intercept $M$; tabel 2 en 3) geven enkel aan dat het gemiddelde beginniveau van de scores op de Big Fivefactoren significant van nul verschilde. Ook de varianties voor de interceptfactoren (Intercept $\mathrm{s}^{2}$ ) verschilden significant van nul, wat aangeeft dat er systematische individuele verschillen in beginniveau (op elfjarige leeftijd) waren.

De gemiddelde hellingscoëfficiënten voor elk van de Big Five-factoren over de vijf leeftijdscohorten geven aan of er gemiddelde lineaire veranderingen in persoonlijkheid over tijd plaatsvonden. De Big Five-factoren Aangenaamheid, Zorgvuldigheid, Emotionele stabiliteit en Openheid vertoonden significante veranderingen van elf tot zeventien jaar voor jongens en meisjes samen. Door rapportages van de adolescent zelf en van de gezinsleden voor jongens en meisjes apart te bekijken, werden nuanceringen van deze bevindingen gevonden. Alleen zelfgerapporteerde Aangenaamheid vertoonde een toename voor zowel jongens als meisjes. Zorgvuldigheid nam alleen toe voor meisjes, zowel in de ogen van de meisjes zelf als in de ogen van hun gezinsleden. Er werd een afname gevonden voor zelfgerapporteerde Emotionele stabiliteit van meisjes en een toename voor Emotionele stabiliteit van jongens gerapporteerd door gezinsleden. Zelfgerapporteerde Openheid nam toe voor jongens en meisjes, maar in de ogen van gezinsleden nam Openheid af voor jongens.

Significante variantie of interindividuele verschillen in groeitrajecten werden vaker gevonden voor zelfgerapporteerde persoonlijkheid dan voor persoonlijkheid gerapporteerd door gezinsleden en vaker voor jongens dan voor meisjes. Significante individuele verschillen in

Tabel 2 Latente groeicurveresultaten voor zelfrapportage van Big Five-factoren.

\begin{tabular}{|c|c|c|c|c|c|c|c|c|c|}
\hline \multirow[b]{2}{*}{ Big Five-factor } & \multicolumn{2}{|c|}{ Intercepten } & \multicolumn{4}{|c|}{ Hellingscoëfficiënten } & \multicolumn{3}{|c|}{ Fit-indices } \\
\hline & $M$ & $\mathrm{~s}$ & M & $\mathrm{s}$ & $?^{2}$ & $\mathrm{df}$ & RMSEA & NNFI & CFI \\
\hline \multicolumn{10}{|l|}{ Extraversie } \\
\hline Adolescenten & $5,05^{* *}$ & $0,59^{* *}$ & $-0,14$ & $0,76^{* *}$ & 31,89 & 26 & 0,02 & 0,99 & 0,99 \\
\hline jongens & $5,02^{* * *}$ & $0,39^{* *}$ & $-0,16$ & $0,98^{* *}$ & 23,99 & 26 & 0,00 & 1,00 & 1,00 \\
\hline meisjes & $5,05^{* *}$ & $0,79^{* *}$ & $-0,04$ & $0,52^{?}$ & 34,67 & 26 & 0,03 & 0,97 & 0,98 \\
\hline \multicolumn{10}{|l|}{ Aangenaamheid } \\
\hline Adolescenten & $5,34^{* *}$ & $0,26^{* *}$ & $0,36^{* *}$ & 0,00 & 49,47 & 26 & 0,04 & 0,94 & 0,95 \\
\hline jongens & $5,27^{* * *}$ & $0,23^{* *}$ & $0,36^{* *}$ & 0,18 & 41,55 & 26 & 0,05 & 0,91 & 0,92 \\
\hline meisjes & $5,43^{* *}$ & $0,23^{* *}$ & $0,35^{* *}$ & 0,00 & 47,33 & 27 & 0,05 & 0,91 & 0,92 \\
\hline \multicolumn{10}{|l|}{ Zorgvuldigheid } \\
\hline Adolescenten & $4,18^{* *}$ & $0,85^{* *}$ & $0,31^{* *}$ & $0,55^{* *}$ & 41,48 & 26 & 0,03 & 0,98 & 0,98 \\
\hline jongens & $4,06^{* *}$ & $0,71^{* *}$ & $0,28^{?}$ & $0,70^{*}$ & 33,68 & 26 & 0,03 & 0,97 & 0,98 \\
\hline meisjes & $4,27^{* *}$ & $0,93^{* *}$ & $0,39^{* *}$ & $0,51^{?}$ & 31,01 & 26 & 0,03 & 0,99 & 0,99 \\
\hline \multicolumn{10}{|c|}{ Emotionele stabiliteit } \\
\hline Adolescenten & $4,53^{* *}$ & $0,44^{* * *}$ & $-0,16^{?}$ & $0,46^{* *}$ & 36,58 & 26 & 0,03 & 0,98 & 0,98 \\
\hline jongens & $4,57^{* *}$ & $0,37^{* *}$ & 0,00 & $0,55^{* *}$ & 31,57 & 26 & 0,03 & 0,97 & 0,97 \\
\hline meisjes & $4,50^{* *}$ & $0,50^{* *}$ & $-0,30^{*}$ & 0,29 & 34,08 & 26 & 0,03 & 0,97 & 0,97 \\
\hline \multicolumn{10}{|c|}{ Openheid voor ervaringen } \\
\hline Adolescenten & $4,72^{* *}$ & $0,43^{* *}$ & $0,41^{* *}$ & $0,23^{*}$ & 44,86 & 26 & 0,04 & 0,97 & 0,97 \\
\hline jongens & $4,71^{* * *}$ & $0,38^{* *}$ & $0,46^{* *}$ & $0,39^{*}$ & 43,38 & 26 & 0,05 & 0,93 & 0,94 \\
\hline meisjes & $4,71^{* * *}$ & $0,50^{* *}$ & $0,39^{* *}$ & 0,07 & 39,34 & 26 & 0,04 & 0,96 & 0,97 \\
\hline
\end{tabular}


Tabel 3 Latente groeicurveresultaten voor Big Five-factoren gerapporteerd door gezinsleden.

\begin{tabular}{|c|c|c|c|c|c|c|c|c|c|}
\hline \multirow[b]{2}{*}{ Big Five-factor } & \multicolumn{2}{|c|}{ Intercepten } & \multicolumn{4}{|c|}{ Hellingscoëfficiënten } & \multicolumn{3}{|c|}{ Fit-indices } \\
\hline & $M$ & $\mathrm{~s}$ & M & $\mathrm{s}$ & $?^{2}$ & $\mathrm{df}$ & RMSEA & NNFI & CFI \\
\hline \multicolumn{10}{|l|}{ Extraversie } \\
\hline Adolescenten & $4,98^{* *}$ & $0,57^{* *}$ & 0,01 & 0,00 & 32,54 & 27 & 0,02 & 0,99 & 0,99 \\
\hline jongens & $4,99^{* *}$ & $0,59^{* *}$ & $-0,15$ & 0,12 & 27,16 & 26 & 0,01 & 0,99 & 0,99 \\
\hline meisjes & $4,98^{* *}$ & $0,52^{* *}$ & 0,14 & 0,00 & 45,34 & 27 & 0,05 & 0,98 & 0,97 \\
\hline \multicolumn{10}{|l|}{ Aangenaamheid } \\
\hline Adolescenten & $5,55^{* *}$ & $0,25^{* *}$ & $-0,07$ & 0,01 & 31,18 & 26 & 0,02 & 0,99 & 0,99 \\
\hline jongens & $5,51^{* *}$ & $0,25^{* *}$ & $-0,14^{?}$ & 0,11 & 25,10 & 26 & 0,00 & 1,00 & 1,00 \\
\hline meisjes & $5,58^{* *}$ & $0,21^{* * *}$ & 0,01 & 0,00 & 33,33 & 27 & 0,03 & 0,99 & 0,99 \\
\hline \multicolumn{10}{|l|}{ Zorgvuldigheid } \\
\hline Adolescenten & $3,98^{* * *}$ & $0,85^{* *}$ & $0,16^{*}$ & 0,18 & 34,99 & 26 & 0,03 & 0,99 & 0,99 \\
\hline jongens & $3,90^{* *}$ & $0,78^{* * *}$ & $-0,09$ & 0,22 & 28,45 & 26 & 0,02 & 0,99 & 0,99 \\
\hline meisjes & $4,07^{* *}$ & $0,87^{* *}$ & $0,38^{* *}$ & 0,00 & 41,24 & 27 & 0,04 & 0,99 & 0,98 \\
\hline \multicolumn{10}{|c|}{ Emotionele stabiliteit } \\
\hline Adolescenten & $4,52^{* *}$ & $0,37^{* * *}$ & $0,20^{* *}$ & 0,12 & 43,40 & 26 & 0,03 & 0,98 & 0,98 \\
\hline jongens & $4,62^{* *}$ & $0,33^{* * *}$ & $0,23^{* *}$ & $0,18^{?}$ & 42,60 & 26 & 0,05 & 0,96 & 0,96 \\
\hline meisjes & $4,43^{* *}$ & $0,40^{* *}$ & $0,16^{?}$ & 0,07 & 27,70 & 26 & 0,02 & 0,99 & 0,99 \\
\hline \multicolumn{10}{|c|}{ Openheid voor nieuwe ervaringen } \\
\hline Adolescenten & $4,91^{* * *}$ & $0,41^{* * *}$ & $-0,07$ & $0,14^{?}$ & 32,13 & 26 & 0,03 & 0,99 & 0,99 \\
\hline jongens & $4,88^{* *}$ & $0,41^{* *}$ & $-0,21^{*}$ & $0,34^{* *}$ & 21,37 & 26 & 0,00 & 1,00 & 1,00 \\
\hline meisjes & $4,96^{* *}$ & $0,38^{* *}$ & 0,03 & 0,33 & 28,21 & 26 & 0,02 & 0,99 & 0,99 \\
\hline
\end{tabular}

${ }^{* *} p<0,01, * p<0,05, ? p<0,10$.

verandering van Extraversie, Zorgvuldigheid, Emotionele stabiliteit en Openheid werden gevonden voor zelfrapportages van jongens en individuele verschillen in verandering van Openheid werden gevonden voor jongens in rapportages van gezinsleden.

Individuele verandering in persoonlijkheid

Naast deze gemiddelde veranderingen onderzochten we of er individuele adolescenten waren die veranderingen in hun persoonlijkheid vertoonden. Hiertoe werd de Reliable Change Index (RCI; Christensen \& Mendoza, 1986; Jacobson \& Truax, 1991) berekend over een periode van twee jaar, van de eerste tot de laatste meetronde. De RCI wordt als volgt berekend:

$$
\mathrm{RC}=\mathrm{x}_{3}-\mathrm{x}_{1} / \mathrm{s}_{\text {diff }}
$$

waarbij $x_{1}$ de score is van een persoon in de eerste meetronde, $x_{3}$ de score van die persoon in de derde meetronde en $\mathrm{s}_{\text {diff }}$ de standaardmeetfout van het verschil tussen de twee scores, die kan worden berekend met de formule voor de standaardmeetfout:

$$
\mathrm{S}_{\mathrm{diff}}=\left(2\left(\mathrm{~S}_{\mathrm{E}}\right)^{2}\right)^{1 / 2}=2^{1 / 2} \mathrm{~S}_{\mathrm{E}}
$$

De standaardmeetfout van de verschilscore geeft de verwachte verdeling van veranderingsscores weer als er geen echte betrouwbare verandering optreedt. RC-scores kleiner dan -1,96 of groter dan 1,96 zijn onwaarschijnlijk zonder dat er echte veranderingen aan ten grondslag liggen en worden daarom als betrouwbaar beschouwd. Als individuele verandering op toeval gebaseerd zou zijn, dan zou de verdeling van RC-scores normaal verdeeld zijn, waarbij 2,5 procent van de respondenten een RCscore hoger dan 1,96 heeft, 2,5 procent een RC-score lager dan -1,96 heeft en 95 procent van de respondenten gelijk blijft. Met andere woorden, bij verandering op basis van toevalsfluctuaties verwachten we dat circa 5 procent van de steekproef een toe- of afname vertoont en 95 procent niet betrouwbaar verandert. De vraag is dus of individuele toe- of afnamen optreden en of deze wel of niet aan toeval toegeschreven kunnen worden.

Tabel 4 toont de percentages adolescenten die een betrouwbare toename of afname vertonen en laat zien dat de meerderheid van de adolescenten gelijk blijft over een periode van twee jaar op elk van de persoonlijkheidsdimensies, maar dat een aanzienlijke minderheid verandering vertoont (9,5 tot $20,8 \%$ voor zelfrapportages, 10,6 tot $29,3 \%$ voor rapportages van gezinsleden). De chikwadraatwaarden laten zien dat voor elke persoonlijkheidsdimensie de verdeling van afnemers, gelijkblijvers en toenemers significant verschilt van de verwachte toevalsveranderingen en daarom niet toegeschreven kan worden aan toeval. Een aanzienlijk deel van de adolescenten laat dus significante betrouwbare veranderingen zien in persoonlijkheidsdimensies in de loop van twee jaar. 
Tabel 4 Percentage betrouwbare veranderaars op Big Five-persoonlijkheidsfactoren.

\begin{tabular}{|c|c|c|c|c|c|c|}
\hline & \multicolumn{6}{|c|}{ Zelfrapportage } \\
\hline & \multicolumn{2}{|c|}{ totaal } & \multicolumn{2}{|c|}{ jongens } & \multicolumn{2}{|c|}{ meisjes } \\
\hline & $-1+$ & $?^{2}$ & $-/+$ & $?^{2}$ & $-1+$ & $?^{2}$ \\
\hline Extraversie & $7,3 / 8,6$ & $141,64^{* * *}$ & $7,7 / 8,1$ & $66,97^{* *}$ & $6,9 / 9$ & $75,49^{* * *}$ \\
\hline Aangenaamheid & $6,2 / 14,6$ & $375,67^{* * *}$ & $8,8 / 16,2$ & $258,46^{* *}$ & $3,8 / 13,1$ & $137,41^{* *}$ \\
\hline Zorgvuldigheid & $9,1 / 11,6$ & $296,41^{* * *}$ & $10,5 / 12,4$ & $187,51^{* *}$ & $7,7 / 10,8$ & $115,22^{* *}$ \\
\hline Emotionele stabiliteit & $6,9 / 5,9$ & $73,18^{* *}$ & $4,7 / 6,2$ & $21,58^{* *}$ & $9 / 5,5$ & $62,21^{* *}$ \\
\hline Openheid voor ervaringen & $3,2 / 6,3$ & $34,44^{* *}$ & $3,3 / 7,4$ & $27,25^{* *}$ & $3,2 / 6,3$ & $9,66^{* *}$ \\
\hline \multirow[t]{3}{*}{ Totaal een of meer veranderingen } & $25 / 33$ & & $27 / 35$ & & $24 / 31$ & \\
\hline & \multicolumn{6}{|c|}{ Rapportage door gezinsleden } \\
\hline & $-1+$ & $?^{2}$ & $-/+$ & $?^{2}$ & $-1+$ & $?^{2}$ \\
\hline Extraversie & $7,4 / 7,4$ & $113,77^{* *}$ & $9,7 / 5,4$ & $70,62^{* *}$ & $5,1 / 9,2$ & $63,58^{* *}$ \\
\hline Aangenaamheid & $10,9 / 8,4$ & $252,21^{* *}$ & $12,3 / 7,2$ & $136,67^{* *}$ & $9,6 / 9,8$ & $122,85^{* *}$ \\
\hline Zorgvuldigheid & $13,3 / 16$ & $716,38^{* * *}$ & $15,5 / 11,6$ & $292,93^{* *}$ & $11,3 / 20,1$ & $476,04^{* *}$ \\
\hline Emotionele stabiliteit & $4,6 / 6,7$ & $51,60^{* *}$ & $4,7 / 5,8$ & $18,09^{* *}$ & $4,4 / 7,5$ & $35,29^{* *}$ \\
\hline Openheid voor ervaringen & $5,3 / 5,3$ & $36,65^{* *}$ & $6,9 / 4,7$ & $27,64^{* *}$ & $3,8 / 5,8$ & $15,26^{* *}$ \\
\hline Totaal een of meer veranderingen & $28 / 32$ & & $35 / 28$ & & $23 / 36$ & \\
\hline
\end{tabular}

Met name op Aangenaamheid en Zorgvuldigheid werd relatief veel individuele verandering geconstateerd. Het percentage adolescenten dat betrouwbare toe- of afnamen vertoonde op persoonlijkheid over tijd was ongeveer gelijk, hoewel er net iets meer toenamen lijken te zijn. Bij de bepaling van de individuele verandering over alle vijf persoonlijkheidsdimensies bleek iets minder dan de helft van de adolescenten op geen enkele persoonlijkheidsdimensie te veranderen over een periode van twee jaar (49\% voor zelfrapportages, $45 \%$ voor rapportages van gezinsleden). Geen enkele adolescent veranderde op alle vijf persoonlijkheidsdimensies, en 5 tot 10 procent veranderde op twee of meer dimensies. Een afname vertoonde 25 tot 28 procent; 32 tot 33 procent vertoonde een toename op ten minste één persoonlijkheidsdimensie. Zowel jongens als meisjes rapporteerden iets meer toenamen dan afnamen, maar andere gezinsleden rapporteerden voor jongens juist meer afnamen.

\section{Discussie}

Het doel van de huidige studie was het onderzoeken van persoonlijkheidsontwikkeling gedurende de adolescentie. Door middel van het schatten van groeicurven voor adolescenten van elf tot zeventien jaar toonden we aan dat persoonlijkheid gedurende deze periode een ontwikkeling doormaakt. De resultaten waren over het algemeen in overeenstemming met onze verwachtingen. De
Emotionele stabiliteit van meisjes bleek zoals verwacht af te nemen, maar alleen voor zelfrapportages. Deze afname in Emotionele stabiliteit komt overeen met een toename in depressieve symptomen voor meisjes in de adolescentie die toegeschreven wordt aan hormonale veranderingen en de sterke interpersoonlijke oriëntatie van meisjes (Crick \& Zahn-Waxler, 2003). Het gebrek aan veranderingen in Emotionele stabiliteit van meisjes in de ogen van andere gezinsleden kan samenhangen met de verminderde zichtbaarheid van deze persoonlijkheidsfactor voor anderen. De toename in Emotionele stabiliteit voor jongens gerapporteerd door gezinsleden was onverwacht en hangt mogelijk samen met seksespecifieke verwachtingen ten aanzien van ouder wordende jongens. Jongens gedragen zich mogelijk stoerder en proberen hun emoties meer te verbergen ten opzichte van hun gezinsleden, wat tot de indruk leidt dat de Emotionele stabiliteit toeneemt.

De verwachte toename in Openheid werd zowel voor jongens als meisjes gevonden, maar alleen voor zelfgerapporteerde Openheid. Openheid gerapporteerd door gezinsleden nam juist af voor jongens. Dit suggereert dat gezinsleden een ander perspectief op de Openheid van adolescenten hebben dan de adolescenten zelf. Toenamen in Openheid hangen mogelijk vooral samen met nieuwe ervaringen buiten het gezin en adolescenten zijn misschien minder graag betrokken bij gezinsactiviteiten, wat de verschillen in perspectief tussen ouders en adolescenten zou kunnen verklaren. De toename in Openheid is mogelijk ook toe te schrijven aan de 
algemene groei in cognitieve competentie gedurende de adolescentie (Allik e.a., 2004).

In overeenstemming met onze verwachtingen werden geen gemiddelde veranderingen in Extraversie gevonden gedurende de adolescentie. Extraversie begint normaal gesproken pas te veranderen in de late adolescentie, wat impliceert dat de adolescenten in het huidige onderzoek niet lang genoeg gevolgd zijn om veranderingen in Extraversie te meten.

Naast deze verwachte veranderingen werden enkele onverwachte veranderingen gevonden. Zorgvuldigheid nam toe voor meisjes, zowel voor zelfrapportages als voor rapportages door andere gezinsleden. Gedurende de vroege adolescentie ondergaan meisjes een snellere groeispurt in cerebraal-corticale ontwikkeling dan jongens en ze blijven op jongens voorlopen in deze ontwikkeling tot veertien tot vijftien jaar (Andrich \& Styles, 1994; Colom \& Lynn, 2004; Lynn, 1999). Als gevolg van deze verschillen in hersenontwikkeling zijn meisjes gedurende de vroege adolescentie over het algemeen ongeveer twee jaar voor op jongens wat betreft intellectueel en sociaal-cognitief functioneren. Jongens zijn minder volwassen dan meisjes in hun morele redeneren (Silberman \& Snarey, 1993) en omgaan met problemen en hebben meer autoriteit- en gedragsproblemen (Porteous, 1985). Deze verschillen kunnen bijdragen aan een eerdere verandering van Zorgvuldigheid voor meisjes vergeleken met jongens. Vanaf zestien jaar en ouder, als de cerebraal-corticale ontwikkeling van meisjes vertraagt in vergelijking met jongens (Colom \& Lynn, 2004), zouden jongens weer inlopen op meisjes.

De veranderingen in Zorgvuldigheid kunnen ook samenhangen met sociale verwachtingen rond opleiding en huishoudelijke taken. Omdat de puberale ontwikkeling van meisjes eerder plaatsvindt dan die van jongens (Paikoff \& Brooks-Gunn, 1991), lijken ze volwassener en roepen ze eerder en hogere verwachtingen op deze gebieden op bij anderen dan jongens.

Jongens en meisjes vertoonden ook een onverwachte toename in zelfgerapporteerde Aangenaamheid. Voor Aangenaamheid gerapporteerd door gezinsleden werd dit niet gevonden; voor jongens werd zelfs het tegenovergestelde patroon gevonden in oordelen van gezinsleden. Wellicht baseren adolescenten hun oordeel van Aangenaamheid op andere situaties dan andere gezinsleden, namelijk situaties met vrienden buiten het gezin in plaats van situaties binnen het gezin. Vriendschapsrelaties worden steeds intiemer wanneer adolescenten ouder worden, wat mogelijk samenhangt met toenamen in Aangenaamheid. Als ouders deze intieme vriendschapsinteracties niet regelmatig observeren, nemen ze mogelijk niet waar dat hun kind aangenamer wordt. Aangezien de kwaliteit van de ouder-kindrelatie over het algemeen licht afneemt gedurende de adolescentie, kunnen adolescenten binnen het gezin zelfs minder aangenaam worden, waardoor gezinsleden hen over tijd als minder aangenaam zien. Blijkbaar is dit met name voor jongens het geval.

Hoewel meer gemiddelde niveauveranderingen in persoonlijkheid werden gevonden voor meisjes dan voor jongens, werden meer interindividuele verschillen in persoonlijkheidsontwikkeling gevonden voor jongens, wat aangeeft dat jongens meer variëren in de timing van persoonlijkheidsveranderingen dan meisjes. Dit komt overeen met eerdere bevindingen (Srivastava e.a., 2003).

De veranderingen in persoonlijkheid suggereren dat adolescenten groeien naar toenemende volwassenheid en adaptatie. Deze veranderingen kunnen een normatieve, levensloopgebonden ontwikkeling weergeven maar ook een historisch en cultureel bepaalde ontwikkeling. Crossculturele vergelijking toont vergelijkbare veranderingen in persoonlijkheid over verschillende landen (McCrae e. a., 1999, 2000, 2002), wat suggereert dat deze ontwikkeling intrinsiek en levensloopgebonden is. Hoewel de gemiddelde veranderingen dergelijke levensloopgebonden ontwikkeling ondersteunen, tonen de individuele verschillen in persoonlijkheidsveranderingen dat er ook variatie in deze ontwikkeling is en suggereren ze dat verschillende ontwikkelingstrajecten beïnvloed zouden kunnen worden door omgevingsinvloeden (vgl. Lewis, 1999). Belangrijke levensgebeurtenissen zijn ook gerelateerd aan veranderingen in persoonlijkheid (Vaidya e.a., 2002; Wink \& Helson, 1993). Wink en Helson vonden bijvoorbeeld dat mannen competenter en vrouwen meer emotioneel afhankelijk en dienstbaar in interpersoonlijke relaties waren als ze jonge kinderen hadden, terwijl deze verschillen kleiner werden of zelfs omkeerden als de kinderen het huis uit waren.

Het onderzoek richtte zich tevens op de vraag in hoeverre veranderingen in persoonlijkheid optreden voor individuele adolescenten. De Reliable Change Index toonde aan dat de meeste adolescenten niet significant veranderden op de afzonderlijke Big Five-factoren gedurende het onderzoek. Adolescenten en hun gezinsleden hebben een relatief consistent beeld van hun persoonlijkheid, zelfs in de turbulente adolescentieperiode. Desondanks bleek een substantieel aantal adolescenten op elk persoonlijkheidsdimensie 'betrouwbare' verandering te vertonen, die niet aan toevallige meetfouten kon worden toegeschreven. Bovendien vertoonde de helft van de adolescenten een verandering op een of meerdere factoren, wat aantoont dat er aanzienlijke intra-individuele verandering in persoonlijkheidsdimensies optreedt. Onze resultaten geven dus duidelijk aan dat sommige adolescenten significant veranderen op een of meer persoonlijkheidsdimensies over een periode van twee jaar. Er werden zowel toenamen als afnamen gevonden voor elk 
van de persoonlijkheidskenmerken, wat overeenkomt met bevindingen van McCrae e.a. (2002), die aantonen dat zelfgerapporteerde toe- en afnamen in zelfgerapporteerde persoonlijkheid elkaar uitmiddelen. Dit suggereert dat de reactie van adolescenten op ontwikkelingstaken in deze periode onvoorspelbaar is; sommige adolescenten worden bijvoorbeeld aardiger en zorgvuldiger, anderen juist minder aardig en zorgvuldig.

Een sterk punt van de huidige studie is het gebruik van een versneld longitudinaal design om groeicurven van persoonlijkheidsontwikkeling te schatten. Het gebruik van dit design maakte het mogelijk persoonlijkheidsontwikkeling te bestuderen van de vroege tot de middenadolescentie en biedt meer inzicht in de ontwikkeling van persoonlijkheid dan cross-sectionele onderzoeken. Door dit design waren we in staat om met data van een kortetermijn-longitudinaal onderzoek de persoonlijkheidsontwikkeling in de adolescentie van elf tot zeventien jaar te onderzoeken. In combinatie met de persoonsgeoriënteerde benadering, die gericht was op het vinden van intra-individuele veranderingen in persoonlijkheid van adolescenten, konden we vaststellen dat er in de adolescentie betrouwbare en betekenisvolle verandering van persoonlijkheid optreedt. Longitudinaal onderzoek naar persoonlijkheidsontwikkeling gedurende de gehele levensloop is echter nodig.

Een ander sterk punt is de meting van zowel zelfgerapporteerde als door gezinsleden gerapporteerde persoonlijkheid. Over het algemeen lijkt het erop dat persoonlijkheid in de ogen van adolescenten zelf vaker verandert dan in de ogen van gezinsleden. De persoonlijkheidsfactoren die veranderden waren ook verschillend voor eigen beoordelingen versus beoordelingen door gezinsleden; soms werden zelfs tegengestelde veranderingen gevonden. Deze bevinding staat in contrast met resultaten van McCrae e.a. (2004), die vonden dat door anderen gerapporteerde persoonlijkheidskenmerken over het algemeen in dezelfde richting veranderden als zelfgerapporteerde persoonlijkheidskenmerken. We vonden geen bewijs dat gezinsleden meer geneigd zijn veranderingen te rapporteren in meer zichtbare factoren zoals Zorgvuldigheid en Openheid, of dat zelfrapportages meer veranderingen vertonen in minder zichtbare factoren zoals Emotionele stabiliteit (Funder \& Dobroth, 1987). Het frequentere veranderen van zelfgerapporteerde persoonlijkheid kan samenhangen met de toenemende deelname van adolescenten in rollen en functies buiten het gezin, waardoor ze zelf een betere observator zijn van hun veranderende persoonlijkheid in deze contexten dan gezinsleden.

Toekomstig onderzoek zou zich ook moeten richten op factoren binnen het individu en in de omgeving die de ontwikkeling van persoonlijkheid zouden kunnen verklaren. De timing van puberteitsontwikkeling in de adolescentie kan bijvoorbeeld de persoonlijkheidsontwikkeling beïnvloeden. Meisjes en jongens die op vroege leeftijd puberteitsveranderingen doormaken, veranderen mogelijk ook eerder in persoonlijkheid. En omdat meisjes meestal eerder puberteitsveranderingen doormaken dan jongens, kan dit misschien ook de verschillen in persoonlijkheidsontwikkeling tussen jongens en meisjes verklaren. Antwoorden op deze vragen leveren waardevolle informatie op over de invloed van intrinsieke en externe factoren op normatieve persoonlijkheidsontwikkeling.

Concluderend heeft dit onderzoek enkele belangrijke bevindingen opgeleverd. We toonden aan dat er normatieve ontwikkelingen in persoonlijkheid plaatsvinden gedurende de adolescentie en dat ook individuele adolescenten betrouwbare veranderingen in persoonlijkheid vertoonden. Daarnaast toonden we aan dat er aanzienlijke individuele variatie is in de mate en aard van veranderingen in persoonlijkheid tijdens de adolescentie.

Ontvangen: 22 maart 2005; geaccepteerd: 10 juni 2005.

Branje, S.J.T., Lieshout, C.F.M. van, Aken, M.A.G. van, \& Gerris, J.R.M. (2005). Development and change in Big Five person ality factors during adolescence. Nederlands Tijdschrift voor de Psychologie, 60, 64-75.

The present study examines development of personality during adolescence. Two adolescent children from 285 two-parent families rated their own and each other's personality in three annual measurement waves, and both parents rated the personality of their children as well. Personality appeared to be stable over time, but for a number of adolescents considerable intra-individual change was found. Accelerated growth curve analyses revealed that Agreeableness and Openness increased for adolescents aged 11 to 17 years and that Conscientiousness increased and Emotional stability decreased for girls only. Results confirm ed that personality development takes place during adolescence, but also showed that the type of change differs for self- and other-reports.

\section{Literatuur}

Allik, J., Laidra, K., Realo, A., \& Pullmann, H. (2004). Personality development from 12 to 18 years of age: Changes in mean levels and structure of traits. European Journal of Personality, $18,445-462$

Andrich, D., \& Styles, I. (1994). Psychometric evidence of intellectual growth spurts in early adolescence. Journal of Early Adolescence, 14, 328-344.

Arbuckle, J.L., \& Wothke, W. (1999). amos4.0 user's guide. Chicago, IL: SmallWaters.

Asendorpf, J.B., \& Aken, M.A.G. van (2003). Validity of Big Five personality judgments in childhood: A 9 year longitudinal study. European Journal of Personality, 17, 1-17.

Baltes, P.B. (1987). Theoretical propositions of life-span developmental psychology: On the dynamics between growth and decline. Developmental Psychology, 23, 611-626.

Biesanz, J.C., West, S.G., \& Kwok, O.-M. (2003). Personality over time: Methodological approaches to the study of short-term 
and long-term development and change. Journal of Personality, 71, 905-941.

Borkenau, P., \& Liebler, A. (1992). Trait inferences: Sources of validity at zero acquaintance. Journal of Personality and Social Psychology, 62, 645-657.

Caspi, A. (2000). The child is father of the man: Personality continuities from childhood to adulthood. Journal of Personality and Social Psychology, 78, 158-172.

Caspi, A. (1998). Personality development across the life course. In W. Damon (Ed.), Handbook of child psychology (5th ed.) (Vol. 3, pp. 311-388). New York: Wiley.

Caspi, A., \& Roberts, B.W. (2001). Personality development across the life course: The argument for change and continuity. Psychological Inquiry, 12, 49-66.

Caspi, A., \& Roberts, B.W. (1999). Personality change and continuity across the life course. In L.A. Pervin \& O.P. John (Eds.), Handbook of personality: Theory and research (2nd ed.) (pp. 300-326). New York: Guilford.

Christensen, L., \& Mendoza, J.L. (1986). A method of assessing change in a single subject: An alteration of the RC index. Behavior Therapy, 17, 305-308.

Colom, R., \& Lynn, R. (2004). Testing the developmental theory of sex differences in intelligence on 12-18 year olds. Personality and Individual Differences, 36, 75-82.

Costa, P.T. Jr., \& McCrae, R.R. (1994). Stability and change in personality from adolescence through adulthood. In C.F. Halverson, Jr. \& G.A. Kohnstamm (Eds.), The developing structure of temperament and personality from infancy to adulthood (pp. 139-150). Hillsdale, NJ: Erlbaum.

Costa, P.T. Jr., \& McCrae, R.R. (1992). Four ways five factors are basic. Personality and Individual Differences, 13, 653-665.

Crick, N.R., \& Zahn-Waxler, C. (2003). The development of psychopathology in females and males: Current progress and future challenges. Development and Psychopathology, 15, 719-742.

De Fruyt, F., Mervielde, I., Hoekstra, H.A., \& Rolland, J.P. (2000). Assessing adolescents' personality with the NEO PI-R. Assessment, 7, 329-345.

Digman, J.M. (1990). Personality structure: Emergence of the fivefactor model. Annual Review of Psychology, 41, 417-440.

Duncan, S.C., Duncan, T.E., \& Strycker, L.A. (2001). Qualitative and quantitative shifts in adolescent problem behavior development: A cohort-sequential multivariate latent growth modeling approach. Journal of Psychopathology and Behavioral Assessment, 23, 43-50.

Funder, D.C. (1980). On seeing ourselves as others see us: Selfother agreement and discrepancy in personality ratings. Journal of Personality, 48, 473-493.

Funder, D.C. (1995). On the accuracy of personality judgment: A realistic approach. Psychological Review, 102, 652-670.

Funder, D.C., \& Colvin, C.R. (1991). Explorations in behavioral consistency: properties of persons, situations, and behaviors. Journal of Personality and Social Psychology, 60, 773-794.

Funder, D.C., \& Dobroth, K.M. (1987). Differences between traits: Properties associated with interjudge agreement. Journal of Personality and Social Psychology, 52, 409-418.

Gerris, J.R.M., Houtmans, M.J.M., Kwaaitaal-Roosen, E.M.G., Schipper, J.C., Vermulst, A.A., \& Janssens, J.M.A.M. (1998). Parents, adolescents, and young adults in Dutch families: A longitudinal study. Nijmegen: Universiteit Nijmegen.

Goldberg, L.R. (1993). The structure of phenotypic personality traits. American Psychologist, 48, 26-34.

Goldberg, L.R. (1992). The development of markers of the BigFive factor structure. Psychological Assessment, 4, 26-42.

Goldberg, L.R. (1990). An alternative 'description of personality': The Big-Five factor structure. Journal of Personality and Social Psychology, 59, 1216-1229.
Graziano, W.G., \& Ward, D. (1992). Probing the Big Five in adolescence: Personality and adjustment during a developmental transition. Journal of Personality, 60, 425-439.

Haselager, G.J.T., \& Aken, M.A.G. van (1999). Codebook of the research project Family and Personality, Vol. 1. First measurement wave. Nijmegen: Universiteit Nijmegen.

Jacobson, N.S., \& Truax, P. (1991). Clinical significance: A statistical approach to defining meaningful change in psychotherapy research. Journal of Consulting and Clinical Psychology, 59, 12-19.

John, O.P. (1990). The 'Big Five' factor taxonomy: Dimensions of personality in the natural language and in questionnaires. In L.A. Pervin (Ed.), Handbook of personality: Theory and research (pp. 66-100). New York: Guilford.

John, O.P., \& Robins, R.W. (1993). Determinants of interjudge agreement on personality traits: The Big Five domains, observability, evaluativeness, and the unique perspective of the self. Journal of Personality, 61, 521-551.

Kenny, D.A., Albright, L., Malloy, T.E., \& Kashy, D.A. (1994). Consensus in interpersonal perception: Acquaintance and the Big Five. Psychological Bulletin, 116, 245-258.

Lewis, M. (1999). On the development of personality. In L.A. Pervin \& O.P. John (Eds.), Handbook of personality: Theory and research (2nd ed.) (pp. 327-346). New York: Guilford.

Lieshout, C.F.M. van (2000). Life-span personality development: Self-organizing goal-oriented agents and developmental outcome. International Journal of Behavioral Development, 24, 276-288.

Lieshout, C.F.M. van, \& Haselager, G.J.T. (1994). The big-five personality factors in Q-sort descriptions of children and adolescents. In C.F. Halverson, G.A. Kohnstamm \& R.P. Martin (Eds.), The developing structure of temperament and personality from infancy to adulthood (pp. 293-318). Hillsdale, $\mathrm{NJ}$ : Erlbaum.

Lynn, R. (1999). Sex differences in intelligence and brain size: A developmental theory. Intelligence, 27, 1-12.

Malloy, T.E., Albright, L., Kenny, D.A., Agatstein, F., \& Winquist, L. (1997). Interpersonal perception and metaperception in nonoverlapping social groups. Journal of Personality and Social Psychology, 72, 390-398.

McCrae, R.R., \& Costa, P.T. Jr. (1999). A Five-Factor theory of personality. In L.A. Pervin \& O.P. John (Eds.), Handbook of personality: Theory and research (2nd ed.) (pp. 139-153). New York: Guilford.

McCrae, R.R., \& Costa, P.T. Jr. (1997). Personality trait structure as a human universal. American Psychologist, 52, 509-516.

McCrae, R.R., \& Costa, P.T. (1994). The stability of personality: Observation and evaluations. Current Directions in Psychological Science, 3, 173-175.

McCrae, R.R., Costa, P.T. Jr., Hebíková, M., Urbánek, T., Martin, A.T., Oryol, V.E., Rukavishnikov, A.A., \& Senin, I.G. (2004). Age differences in personality traits across cultures: Self-report and observer perspectives. European Journal of Personality, 18, 143-157.

McCrae, R.R., Costa, P.T. Jr., Terracciano, A., Parker, W.D., Mills, C.J., De Fruyt, F., \& Mervielde, I. (2002). Personality trait development from age 12 to age 18: Longitudinal, crosssectional and cross-cultural analyses. Journal of Personality and Social Psychology, 83, 1456-1468.

McCrae, R.R., Costa, P.T. Jr., Ostendorpf, F., Angleitner, A., Hrebickova, M., Avia, M.D., Sanz, J., Sanchez-Bernardos, M.L., Kusdil, M.E., Woodfield, R., Saunders, P.R., \& Smith, P.B. (2000). Nature over nurture: Temperament, personality, and life span development. Journal of Personality and Social Psychology, 78, 173-186.

McCrae, R.R., Costa, P.T., Pedroso de Lima, M., Simoes, A., Ostendorf, F, Angleitner, A., e.a. (1999). Age differences in 
personality across the adult life span: Parallels in five cultures. Developmental Psychology, 35, 466-477.

Mehta, P.D., \& West, S.G. (2000). Putting the individual back into individual growth curves. Psychological Methods, 5, 23-43.

Paikoff, R.L., \& Brooks-Gunn, J. (1991). Do parent-child relationships change during puberty? Psychological Bulletin, 110, 47-66.

Porteous, M.A. (1985). Developmental aspects of adolescent problem disclosure in England and Ireland. Journal of Child Psychology and Psychiatry and Allied Disciplines, 26, 465-478.

Raudenbush, S.W., \& Chan, W.S. (1993). Application of a hierarchical linear model to the study of adolescent deviance in an overlapping cohort design. Journal of Consulting and Clinical Psychology, 61, 941-951.

Roberts, B.W., Caspi, A., \& Moffitt, T.E. (2001). The kids are alright: Growth and stability in personality development from adolescence to adulthood. Journal of Personality and Social Psychology, 81, 670-683.

Roberts, B.W., \& Del Vecchio, W.F. (2000). The rank-order consistency of personality from childhood to old age: A quantitative review of longitudinal studies. Psychological Bulletin, 126, 3-25.

Robins, R.W., Fraley, R.C., Roberts, B.W., \& Trzesniewski, K.H. (2001). A longitudinal study of personality change in young adulthood. Journal of Personality, 69, 617-640.

Robins, R.W., John, O.P., \& Caspi, A. (1994). Major dimensions of personality in early adolescence: The Big Five and beyond. In
C.F. Halverson, Jr. \& G.A. Kohnstamm (Eds.), The developing structure of temperament and personality from infancy to adulthood (pp. 267-291). Hillsdale, NJ: Erlbaum.

Shiner, R.L. (1998). How shall we speak of children's personalities in middle childhood? A preliminary taxonomy. Psychological Bulletin, 124, 308-332.

Silberman, M.A., \& Snarey, J. (1993). Gender differences in moral development during early adolescence: The contribution of sex-related variations in maturation. Current Psychology, 12, 163-171

Srivastava, S., John, O.P., Gosling, S.D., \& Potter, J. (2003). Development of personality in early and middle adulthood: Set like plaster or persistent change? Journal of Personality and Social Psychology, 84, 1041-1053.

Stein, J.A., Newcomb, M.D., \& Bentler, P.M. (1986). Stability and change in personality: A longitudinal study from early adolescence to young adulthood. Journal of Research in Personality, 20, 276-291.

Vaidya, J.G., Gray, E.K. Haig, J., \& Watson, D. (2002). On the temporal stability of personality: Evidence for differential stability and the role of life experiences. Journal of Personality and Social Psychology, 83, 1469-1484.

Wink, P., \& Helson, R. (1993). Personality change in women and their partners. Journal of Personality and Social Psychology, $65,597-606$ 